\title{
Clinical Features of the Gastric Signet Ring Cell Carcinoma Including CA 19- 9, CEA and CRP Levels
}

Bulent Kaya ${ }^{1 *}$, Hasan Abuoglu', Cengiz Eris ${ }^{1}$, Mehmet Kamil Yildiz $^{1}$, Orhan Bat ${ }^{2}$, Mehmet Odabasi', Nuriye Esen Bulut ${ }^{3}$, Alper Şahbaz ${ }^{2}$, Aziz Şener ${ }^{2}$, Azamet Çezik ${ }^{2}$ and Umit Topaloglu'

${ }^{1}$ Haydarpasa Numune Training and Research Hospital, Istanbul, Turkey

${ }^{2}$ Kanuni Sultan Suleyman Training and Research Hospital, Istanbul, Turkey

${ }^{3}$ Fatih Sultan Mehmet Training and Research Hospital, Istanbul, Turkey

\begin{abstract}
Aim: The aim of this study was to evaluate the clinicopathological features and prognosis of gastric Signet Ring Cell Carcinoma (SRCC) including measurement of tumor markers (CEA, CA 19-9) and CRP.

Material and method: There were 19 patients with histopathological diagnosis of signet ring cell carcinoma of the stomach. Clinicopathological parameters, including gender and age of the patients, duration of symptoms, size and location of tumors, depth of invasion ( $\mathrm{T}$ stage), lymph node metastasis status ( $\mathrm{N}$ stage), distant metastasis ( $\mathrm{M}$ status) and operative details, were collected retrospectively. CEA, CA 19-9 and CRP levels were measured in all patients.

Results: The mean age of the patients was $63.74 \pm 15.07$ (range 37-90 years). Median survival time was $17.4 \pm$ 10.7 month (range 4-48 months). The mean CA 19-9 level was $14.4 \pm 23.1$ (0.8-101.6), CEA level was $91.9 \pm 227.2$ (0.46-989) and CRP level was $1.79 \pm 1.19$ (0.3-3.7). Sixteen patients were classified as stage III or IV disease. Five patients were operated with total gastrectomy and 9 patients with gastroenterostomy due to unresectable tumor.

Conclusion: Clinicopathological behavior of gastric SRCC is still debated. In this serial, most of the patients with gastric SRCC were diagnosed and treated in last stages of their diseases. Although CA 19-9 and CEA levels were inceased in some patients with SRCC, diagnostic value of these markers is debated.Another marker CRP was found normal in most of the patients with gastric SRCC in this serial.
\end{abstract}

Keywords: Tumors; Lymph nodes; Carcinoma; Metastasis

\section{Introduction}

Although gastric carcinoma shows declining incidence in last years, it is one of the gastrointestinal cancer with high morbidity and mortality. World Health Organization (WHO) was classified the gastric adenocarcinoma into four predominant histological types. These are tubular adenocarcinoma, papillary adenocarcinoma, mucinous adenocarcinoma (MAC) and signet ring cell carcinoma (SRCC) [1]. SRCC is a descriptive term used for a specific type of mucin-producing adenocarcinoma. Intracytoplasmic mucin pushes the nuclei one side of cell and cause the typical appreance of signet ring in these tumor cells. Approximately $95 \%$ of SRCC originates from stomach. It can also be arised from colon, breast, gallbladder and pancreas [2]. The clinicopathological characteristics and prognosis in patients with SRCC of the stomach are still controversial. Some studies reported that early-stage gastric SRCC was associated with a better prognosis than non-SRCC, others claimed that SRCC had a prognosis similar to nonSRCC [3-8].

Many tumor markers can be useful for the management of patients with cancer. Carcinoembryonic antigen (CEA), carbohydrate antigen and (CA 19.9) were used in follow-up of patients with gastric cancer. But their role in diagnosis is debated. The aim of this study was to evaluate the clinicopathologic features and prognosis of gastric SRCC including the role of tumor markers (CEA,CA 19-9) and CRP in this disease.

\section{Material and Methods}

Between 2005 and 2013, a total of 125 patients diagnosed with gastric cancer were operated. There were 19 patients with histopathological diagnosis of signet ring cell carcinoma of the stomach. Preoperative evaluation of all patients with gastric cancer were performed with routine laboratory test, abdominal and thorax computed tomography. The tumors markers including CA 19-9,CEA and CRP levels were measured in all patients. Normal value for CA 19-9 was 0-37 U/l, for CEA was $<5 \mathrm{ng} / \mathrm{dl}$ and for CRP was $0-3 \mathrm{mg} / \mathrm{L}$. The surgical operations were performed by same four experienced surgeon. Patients were underwent either curative or palliative surgery according to preoperative radiological examinations and exploratory findings.

The tissue samples had been fixed routinely in $10 \%$ neutral formalin and embedded in paraffin. Signet ring cell carcinoma was diagnosed when adenocarcinoma was seen with a predominant component $(>50 \%)$ of isolated tumor cells in tissue specimen. Clinicopathological parameters, including gender and age of patients; duration of symptoms, size and location of tumors; depth of invasion (T stage); lymph node metastasis status ( $\mathrm{N}$ stage); distant metastasis ( $\mathrm{M}$ status) and operative details, were collected retrospectively. All patients were followed up after surgery with regular follow-up; these included the determination of tumor marker levels, abdominal computed tomography (CT) and endoscopic examination.

*Corresponding author: Bulent Kaya, Kanuni S.S Training and Research Hospital, Department of General Surgery, Turgut Özal Cd. No: 1, Zip Code: 34303 Kucukcekmece, İstanbul, Turkey, Tel: 05056822101; E-mail: drbkaya@yahoo.com

Received December 15, 2014; Accepted April 16, 2015; Published April 20, 2015

Citation: Kaya B, Abuoglu H, Eris C, Yildiz MK, Bat O, et al. (2015) Clinical Features of the Gastric Signet Ring Cell Carcinoma Including CA 19-9, CEA and CRP Levels. J Cancer Sci Ther 7: 127-129. doi:10.4172/1948-5956.1000336

Copyright: (๑) 2015 Kaya B, et al. This is an open-access article distributed under the terms of the Creative Commons Attribution License, which permits unrestricted use, distribution, and reproduction in any medium, provided the original author and source are credited. 
Citation: Kaya B, Abuoglu H, Eris C, Yildiz MK, Bat O, et al. (2015) Clinical Features of the Gastric Signet Ring Cell Carcinoma Including CA 19-9, CEA and CRP Levels. J Cancer Sci Ther 7: 127-129. doi:10.4172/1948-5956.1000336

Statistical analysis was performed by using the SPSS 17 program (Statistical Package for Social Science).

\section{Results}

There were 19 patients (\% 15.8) with histopathological diagnosis of signet ring cell carcinoma of the stomach in this serial.There were 12 male and 7 female patients. The mean age of the patients were $63.74 \pm 15.07$ (Range: 37-90 years). Median survival was $17.4 \pm 10.7$ months (Range:4-48 months) (Table 1). The most common preoperative symptom was abdominal pain in 9 patients $(47.3 \%)$ and weight loss in 9 patients (47.3\%) (Table 2). The mean CA 19-9 level was $14.4 \pm 23.1(0.8-101.6)$, CEA level was $91.9 \pm 227.2(0.46-989)$ and CRP level was $1.79 \pm 1.19$ (0.3-3.7).The localization of gastric lesions; 3 in cardia, 4 in corpus and 12 in antrum and pilor. Five patients were operated with total gastrectomy and 9 patients with gastroenterostomy due to unresectable tumor (Table 3). Exploration findings were shown in (Table 4). There were 5 patients with stage IV disease. The stages of all patients were shown in (Table 5 ). There were 2 early postoperatif complications one pancreatitis an one atelectasis. There were no postoperative mortality.

\section{Discussion}

Gastric cancer (GC) remains a second most common cause of cancer-related death worldwide. Its incidence has markedly declined over the past decades all over the world. The prognosis for advanced gastric cancer is poor when curative resection is not suitable. The early detection of gastric cancer is one of the most important subject of oncological surgeons worldwide.

Signet-ring cell carcinoma (SRCC), a mucin-producing adenocarcinoma, can originate from all organs. However, more than $90 \%$ of cases of human SRCC arise from the stomach, breast, and colon. SRCC comprises about 8.7 percent of all gastric cancers [7]. It is reported to occur more frequently among women and young patients [8]. SRCC is usually presented with infiltration of the gastric wall diffusely. It also has a tendency for more extensive and infiltrative growth, lymph node and distant metastasis including peritoneal dissemination $[9,10]$. It is usually classified as poorly-differentiated tumor.It is most commonly located in antral region. Although clinical

\begin{tabular}{llc|}
\hline Parameters & Mean \pm SD & Min-Max \\
Age & $63.74 \pm 15.07$ & $(37-90)$ \\
CA 19-9 & $14.4 \pm 23.1$ & $(0.8-101.6)$ \\
CEA & $91.9 \pm 227.2$ & $(0.46-989)$ \\
AFP & $8.47 \pm 20.1$ & $(0.97-90)$ \\
Alb & $3.45 \pm 0.45$ & $(2.6-4.2)$ \\
CRP & $1.79 \pm 1.19$ & $(0.3-3.7)$ \\
Hgb & $10.79 \pm 2.22$ & $(7-14.1)$ \\
Htc: & $32.9 \pm 6.3$ & $(22.2-44.1)$ \\
Sedimentation & $29.77 \pm 20.45$ & $(12-85)$ \\
$\begin{array}{l}\text { Duration of symptoms } \\
\text { (Months) }\end{array}$ & $7.79 \pm 5.96$ & $(1-24)$ \\
$\begin{array}{l}\text { Hospitalization } \\
\text { (Days) }\end{array}$ & $9.47 \pm 2.27$ & $(7-15)$ \\
$\begin{array}{l}\text { Table 1: Baseline characteristics } \\
\text { stomach. }\end{array}$ & patients with signet ring & \\
\hline
\end{tabular}

\begin{tabular}{|c|c|}
\hline Symptom & Number of patients \\
\hline Abdominal pain & $\mathbf{9}$ patients \\
\hline Weight loss & $\mathbf{9}$ patients \\
\hline Anorexia & $\mathbf{3}$ patients \\
\hline Vomiting & $\mathbf{4}$ patients \\
\hline Weakness & $\mathbf{4}$ patients \\
\hline Melena & $\mathbf{1}$ patient \\
\hline Dispepsia & $\mathbf{2}$ patients \\
\hline
\end{tabular}

Table 2: Preoperative symptoms.

\begin{tabular}{|c|c|}
\hline Type of surgery & Number of patients(\%) \\
\hline Total gastrectomy + Gastrojejenostomy & $5(26.3 \%)$ \\
\hline Subtotal gastrectomy + Gastrojejenostomy & $5(26.3 \%)$ \\
\hline Gastroenterostomy & $9(47.3 \%)$ \\
\hline \multicolumn{2}{|c|}{ Table 3: Surgical procedures. } \\
\hline Exploration findings & Number of patients(\%) \\
\hline \multicolumn{2}{|l|}{ Mass lesion } \\
\hline in antrum & $8(42.1 \%)$ \\
\hline in cardia & $4(21 \%)$ \\
\hline in corpus & $3(15.7 \%)$ \\
\hline Gastric wall thickening & $1(5.2 \%)$ \\
\hline Gato formation with colon and omentum & $3(15.7 \%)$ \\
\hline Metastasis to liver and or omentum & $5(26.3 \%)$ \\
\hline in antrum & $8(42.1 \%)$ \\
\hline Invasion of transverse colon & $3(15.7 \%)$ \\
\hline
\end{tabular}

Table 4: Exploration findings of all patients.

\begin{tabular}{|c|c|c|}
\hline TNM & Number of patients & Stage \\
\hline T2 N1 Mo & 1 patient & IIA \\
\hline T2 N2 Mo & 2 patients & IIB \\
\hline T3 N2 M0 & 4 patients & IIIA \\
\hline T3 N2 M1 & 1 patient & IV \\
\hline T3 N3 M1 & 1 patient & IV \\
\hline T4b N2 MO & 1 patient & IIIC \\
\hline T4b N2 M1 & 1 patient & IV \\
\hline T4a N3 MO & 6 patients & IIIC \\
\hline T4a N3 M1 & 2 patients & IV \\
\hline
\end{tabular}

Table 5: TNM stages of patients.

behaviour of SRCC is contraversial, the diagnosis and treatment of SRCC is not different than adenocarcinoma.

Most researchers claimed that gastric SRCC is a poorly differentiated lesion with high invasive tendency with poor prognosis. However, the overall clinicopathological behaviour of SRCC is still controversial when compared with other subtypes of gastric carcinoma. SRCC histology was not accepted as an independent prognostic factor [2,7]. Hyung et al. [11] reported that the patients with early gastric SRCC have higher survival rates than those with other types of early gastric cancer. In contrast, Yokota et al. [2] and Theuer et al. [12] respectively found that the 5-year survival rate of gastric SRCC is significantly lower than other types and the prognosis for gastric carcinomas with SRC components was worse than those without SRC components. Taghavi $S$ et al. studied 2,666 patients with SRCC in asian population [13]. They compared these patients with gastric adenocarcinoma.They stated that SRCC was not associated with worse prognosis. These studies showed that the clinopathological features of gastric SRC carcinoma is contraversial. 
Citation: Kaya B, Abuoglu H, Eris C, Yildiz MK, Bat O, et al. (2015) Clinical Features of the Gastric Signet Ring Cell Carcinoma Including CA 19-9, CEA and CRP Levels. J Cancer Sci Ther 7: 127-129. doi:10.4172/1948-5956.1000336

Most of the our patients with SRCC were presented with advanced stage of their disease in this study. Sixteen patients were classified as stage III or IV disease. Nine patients were operated with palliative measures mainly by gastroenterostomy. Five patients presented with distant metastasis including liver metastasis or carcinomatosis peritonei. The preoperative symptoms were detected for about 8 months before admition to hospital. This is relatively a long time for gastric cancer. Delay in admision can be a reason for advanced diseases of these patients.

Although there is no spesific tumor marker for gastric cancer, It was claimed that high levels of CEA, CA 19-9, in gastric cancer patients associated with advanced tumor stage. There is strong association between tumor marker levels and tumor stage, depth and lymph node involvement. Kodera et al., reported that CEA strongly correlates with serosal invasion, lymph node involvement and advanced stage in gastric cancer [14]. On the other hand Gwak et al. showed that there was no significant relationship between CA 19-9 and depth of tumor invation, nodal status and staging except metastasis, CEA did not also show statistically significant relationship with nodal involvement, depth of invasion and stage [15].

The potential significance of C-reactive protein (CRP) has also been suggested as a prognostic marker of many malignancies, including gastric cancer [16,17]. Lukaszewicz-Zając $M$ et al. [18] showed that CRP and CA 19-9 were significantly higher in patients with nonresectable gastric tumor in comparison with the resectable cases. They also observed that the concentrations of CRP and classic tumor markers were higher in the sera of patients who died of gastric cancer when compared to patients who survived. In our study both tumor markers (CA 19-9,CEA) and CRP were not found as good indicators for advanced gastric SRCC. The mean CRP levels were within normal limits.

In conclusion, clinicopathological behavior of SRCC is still debated. In this serial, most of the patients with SRCC were diagnosed and treated in last stages of their diseases. Although it was not the primary goal of this study inflamatory marker, CRP and other tumor markers were not helpful for detecting advanced cases with gastric SRCC. This study has also some limitations due to small sample size. The clinical studies with larger patient groups can be beneficial to show the further clinical features of SRCC.

\section{References}

1. Watanabe H, Jass JR, Sobin LH (1990) Histological typing of esophageal and gastric tumors: WHO international histological classification of tumors. (2ndedtn) Springer, Berlin.

2. Yokota T, Kunii Y, Teshima S, Yamada Y, Saito T, et al. (1998) Signet ring cell carcinoma of the stomach: a clinicopathological comparison with the other histological types. Tohoku J Exp Med 186: 121-130.

3. Chiu CT, Kuo CJ, Yeh TS, Hsu JT, Liu KH, et al. (2011) Early signet ring cell gastric cancer. Dig Dis Sci 56: 1749-1756.

4. Jiang CG, Wang ZN, Sun Z, Liu FN, Yu M, et al. (2011) Clinicopathologic characteristics and prognosis of signet ring cell carcinoma of the stomach: results from a Chinese mono-institutional study. J Surg Oncol 103: 700-703.

5. Kunisaki C, Shimada H, Nomura M, Matsuda G, Otsuka Y, et al. (2004) Therapeutic strategy for signet ring cell carcinoma of the stomach. $\mathrm{Br} \mathrm{J}$ Surg 91: 1319-1324.

6. Otsuji E, Yamaguchi T, Sawai K, Takahashi T (1998) Characterization of signet ring cell carcinoma of the stomach. J Surg Oncol 67: 216-220.

7. Kim DY, Park YK, Joo JK, Ryu SY, Kim YJ, et al. (2004) Clinicopathological characteristics of signet ring cell carcinoma of the stomach. ANZ J Surg 74 1060-1064.

8. Zhang M, Zhu G, Zhang H, Gao H, Xue Y (2010) Clinicopathologic features of gastric carcinoma with signet ring cell histology. J Gastrointest Surg 14: 601606.

9. Yamashiro K, Suzuki H, Nagayo T (1977) Electron microscopic study of signetring cells in diffuse carcinoma of the human stomach. Virchows Arch A Patho Anat Histol 374: 275-284.

10. Kubota K, Yamada S, Ito M, Nakamura W, Nagayo T (1977) Cytoplasmic leucine naphthylamidase activity expressed in signet-ring cell carcinoma of the stomach. J Natl Cancer Inst 59: 1599-1604.

11. Hyung WJ, Noh SH, Lee JH, Huh JJ, Lah KH, et al. (2002) Early gastric carcinoma with signet ring cell histology. Cancer 94: 78-83.

12. Theuer CP, Nastanski F, Brewster WR, Butler JA, Anton-Culver H (1999) Signet ring cell histology is associated with unique clinical features but does not affect gastric cancer survival. Am Surg 65: 915-921.

13. Taghavi S, Jayarajan SN, Davey A, Willis Al (2012) Prognostic significance of signet ring gastric cancer. J Clin Oncol 30: 3493-3498.

14. Kodera Y, Yamamura Y, Torii A, Uesaka K, Hirai T, et al. (1996) The prognostic value of preoperative serum levels of CEA and CA19-9 in patients with gastric cancer. Am J Gastroenterol 91: 49-53.

15. Gwak HK, Lee JH, Park SG (2014) Preliminary evaluation of clinical utility of CYFRA 21- CA 72-4, NSE, CA19-9 and CEA in stomach cancer. Asian Pac J Cancer Prev 15: 4933-4938.

16. Kim DK, Oh SY, Kwon HC, Lee S, Kwon KA, et al. (2009) Clinical significances of preoperative serum interleukin-6 and C-reactive protein level in operable gastric cancer. BMC Cancer 9: 155

17. Kai H, Kitadai $Y$, Kodama M, Cho S, Kuroda T, et al. (2005) Involvement of proinflammatory cytokines IL-1beta and IL-6 in progression of human gastric carcinoma. Anticancer Res 25: 709-713.

18. Lukaszewicz-Zając M, Mroczko B, Gryko M, Kędra B, Szmitkowski M (2011) Comparison between clinical significance of serum proinflammatory proteins (IL-6 and CRP) and classic tumor markers (CEA and CA 19-9) in gastric cancer. Clin Exp Med 11: 89-96. 